\title{
3D Modelling and Visualization in Field Archaeology. From Survey To Interpretation Of The Past Using Digital Technologies
}

\begin{abstract}
Over the last few decades, there has been a growing interest in the fusion of the humanities and the hard sciences. The continuous experimentation and contamination between these two disciplines has led to the emergence of new horizons of research and open to perspectives and issues previously unthinkable. Finally, it has started the development of specific technologies for the cultural domain. Among these technologies, virtual archaeology, which we could define as the set of processes of acquisition, analysis and interpretation aimed at visualizing and simulating the past using 3D digital technologies and a theoretical and multidisciplinary scientific approach, has now reached its maturity. In this contribution the potentials in using 3D modelling as a tool of investigation and visualization for a deeper understanding of archaeological sites is presented. The discussion is supported by the case study of the roman villa of Aiano, built at the beginning of the 4th century A.D. and characterized by monumental architecture and decorations.
\end{abstract}

\section{Introduction}

This paper focuses on the use of digital 3D technologies in archaeology and the potential of computer-based visualization as research tools to support the interpretation and modelling of archaeological data.

Very often, in fact, graphic models of ancient artefacts and architectures are excluded from the interpretative process and are only considered as mere communicative visualization or public fiction rather than scientific tools'. The application of 3D modelling and visualization tools, if integrated in the cognitive and interpretative process, following a systematic scientific approach, can lead to a deeper understanding of the archaeological context ${ }^{2}$. After a discussion on the current state of the art computer-based visualization in archaeology, some theoretical aspects necessary for the creation of a reliable project of virtual archaeology will be discussed.

1 Demetrescu 2018

2 Ask 2012, 9-10 
In the second part of this article we will describe a proven workflow of 3D modelling and visualization in archaeology applied to the case study of the Roman villa of Aiano. It will be deepened how the 3D model of the archaeological excavation, acquired with photogrammetric techniques, has been used in combination with the reconstructive 3D model. It will also be described how the reconstructive process has been traced through the registration of sources and paradata used to ensure the transparency of the process of archaeological interpretation.

\section{Dealing with the reconstruction of the past}

The use of computer-based visualization to show hypothetical reconstruction of the past within the Cultural Heritage domain dates back to the end of the 80s. However, as Clarks points out, the idea of reconstructing the past has been part of archaeology almost since its origins. In 1990, Paul Reilly, with his paper: "Towards a virtual archaeology", formalised for the first time the term "Virtual Archaeology" to describe the use of computer-based simulations of archaeological excavations ${ }^{3}$. In the last two decades with the development of computer graphic technology, computer-based visualization has made enormous progress in terms of graphics rendering and realism. This development has also had a great impact on virtual archaeology ${ }^{4}$. The main consequence is that the Reilly's concept $t^{5}$ of "simulation" has been lost in sight and the term "reconstruction" has been widely used to refer to these visualizations. Many archaeologists have criticized this term as it could be misleading since the 3D model of the past are tools for better understanding the past and not statements of reality ${ }^{6}$. Given the idiom "seeing is believing", the realism achieved by modern visualization systems could lead the users to perceive the virtual model as "truth" instead of a result of interpretation. For this reason, every virtual reconstruction should have adequate mechanisms to declare the level of authenticity allowing to distinguish what is real from what is interpreted. Clark ${ }^{7}$ complains that most virtual reconstruction are not provided with such mechanisms. This is often due to the fact that making transparent all the sources that led to the development of a hypothetical reconstruction is not easy, especially when dealing with complex contexts or conflicting information. These criticisms were certainly also generated by the fact that the first applications of virtual reality for 3D visualization of archaeological data had several weaknesses. As Forte ${ }^{8}$ underlines, in the first applications of virtual reality for $3 \mathrm{D}$ visualization of archaeological data

3 Reilly 1990, 133

4 See Barceló et al. 2000, Frisher et al. 2002, Sanders 2008

5 Reilly 1990, 133

6 Clark 2010, Forte 2010, Baker 2012

7 Baker 2012, 164

8 Forte 2000 
there was a lack of consistent virtual archaeological projects aimed at finding precise answers using digital technologies. In fact, many projects were more focused on technological spectacularization and dissemination aspects rather than scientific research. The first models were not "transparent", in respect to the sources and the reconstructions were presented as peremptory without offering alternative hypotheses. Finally, there was a lack of interdisciplinary professionals who would have linked the humanities with the computer world. Indeed, despite prudences and criticisms, many benefits have been considered by the scientific community. Sanders in "Why do virtual heritage" explain the specific benefits of using interactive 3D modeling in the field of cultural heritage saying that it is not merely visualization but it "takes advantage of the digital medium to [...] produce new insight into the past, which after all is what archaeology is supposed to be all about". According to him, among others, virtual heritage is the better way to test complex hypotheses, to visualise intrasite change and development and to visually absorb complex dataset about the past. Hermon and Nikodem also emphasize the use of 3D modeling as a research tool and underlines the cognitive value of $3 \mathrm{D}$ visualization as it facilitates the understanding of complex information ${ }^{10}$. Over the years, methods, theory and principles have been developed to regulate the use of computer-based visualization by scientific community.

\section{The Intellectual transparency}

As described above, a project of virtual archaeology requires a scientific approach to get a consistent and thorough visualization model of the past and in order to avoid the ambiguity of the "black box effect"" (reconstructive models seem to be fictional despite they have been made following a scientific approach). As a result of the scientific debate on virtual reconstruction, numerous projects and documents aimed at creating efficient guidelines and good practices in the field of scientific visualization of the past have been implemented over the years such as the London Charter ${ }^{12}$ and Seville Principles ${ }^{13}$. Scientific project and consortiums also have contributed to the research providing tool and support, as in the case of $3 \mathrm{DVisa}^{14}$, V-Must ${ }^{15}$ and also Ariadne infrastructure ${ }^{16}$ and $3 \mathrm{D}-$ coform $^{17}$ (even if the latter are

\footnotetext{
9 Sanders 2008, 564

10 Hermon and Nikodem 2007

11 Demetrescu 2018, 105

12 http://www.londoncharter.org/preamble.html

$13 \mathrm{http} / / /$ sevilleprinciples.com/

14 http://3dvisa.cch.kcl.ac.uk/index.html

15 http://www.v-must.net/

$16 \mathrm{https://ariadne-infrastructure.eu/}$

17 http://www.3d-coform.eu/
} 
Fig. 1. A) aerial view of the archaeological site. At the top right the foundations of the trefoil hall and ambulatio are still visible. The red arrow highlights the position of the detail $B$ within the site; $B)$ detail of the preserved floor of the trefoil hall. more oriented towards digitization and visualization services). These initiatives arise from the awareness of the potential of computer-based visualization of heritage but also from the need for a theoretical debate and principles with practical implications to regulate its use and minimize its weaknesses and inconsistencies.

The London Charter is one of the most internationally-recognized documents which defines a set of principle of computer-based visualization to ensure the intellectual and technical integrity, reliability, documentation, sustainability and accessibility ${ }^{18}$. In particular it points out the importance of structuring and documenting not only the sources used and their metadata but also the interpretation made to achieve the visual representation. This aspect is particularly important when dealing with virtual reconstruction ${ }^{19}$.

In the next sections after a brief description of the case study, the workflow adopted to achieve 3D hypothetical reconstruction of archaeological records and the scientific approach used to deal with sources and paradata management and uncertainty problems, will be illustrated.

\section{The case study}

Since 2005, an Italian-Belgian mission coordinated by the UCLouvain as part of the international project "VII Regio. The Elsa Valley during Roman Age and Late Antiquity", has carried out numerous excavation campaigns in the area of Aiano, near San Gimignano, in a site of great interest for the significant findings of the
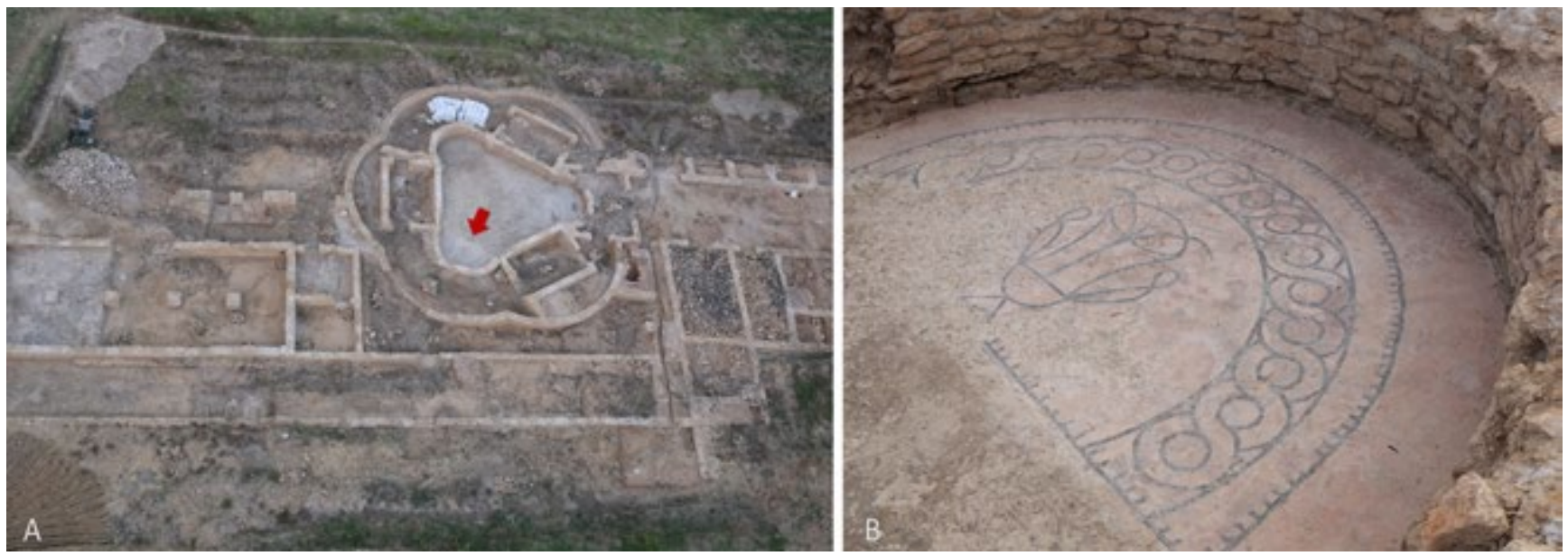

18 Beacham, Denard and Niccolucci 2012, Denard 2012, Denard 2013, Hermon, Sorin and Niccolucci 2018

19 Ferdani et al. 2014 
Roman era (IV - VII century A.D.). During the archaeological excavations, researchers identified a villa probably built between the end of the 3rd and the beginning of the 4th century A.D. with monumental architecture and decorations (fig. 1).

The $2005-2019$ campaigns led to the discovery of a villa of 10.000 square me$\operatorname{tres}^{20}$. Only one third of the surface has been excavated at this moment. The oldest building, dates back between the late 3rd and the early 4th cent. $\mathrm{AD}$ and is located in the S-W area of the settlement: only the foundation walls are left. Between the late 4 th and the late 5 th cent. $\mathrm{AD}$, the entire settlement underwent a monumental rearrangement, which turned it into a veritable architectural unicum $^{21}$.

The chief feature was a six-foil hall surrounded by a corresponding ambulatio. According to archaeological records, at the beginning of the fifth century, three foils were destroyed, and three little rectangular rooms replaced them. The central room became a trefoil hall, with a floor decorated with mosaic details in geometrical and figurative patterns - the only surviving floor of the entire villa ${ }^{22}$. This room was surrounded by a polylobed ambulatio, thus becoming an architectural unicum. Between the late 5th and the mid-6th cent. AD the villa was abandoned, and new workshops were set up; the furnishings and building materials were taken away to be melted, recycled and reused ${ }^{23}$.

When found, the decorations of the villa (marble, glass sectilia, mosaics, frescoes and stuccoes) had been deprived of their original purposes, since they had been disassembled or recycled during the last stage in the life of the site ${ }^{24}$. The site was completely abandoned during the seventh century AD.

\section{Methods into practice}

The process of creating hypothetical models of the past (objects, buildings or sites) is the most challenging and complex task to be performed by researchers. It is strictly connected to a meticulous work of philological interpretation based both on a combination of data derived from several heterogeneous sources and on the involvement of different professionals (archaeologists, expert in different subjects, heritage architects, historians etc.). The quality and completeness of the modelling is influenced both by the quality of the data collected and by the way in which these data are cross-referenced and analyzed to propose reconstructive hypotheses.

20 Cavalieri and Pace 2011.

21 See in particular: Cavalieri, Pace and Lenzi 2019

22 Cavalieri 2010: the floor is a "cementizio"

23 Cavalieri, Lenzi and Cantisani 2013, Deltenre and Orlandi 2016

24 Cavalieri 2009, Cavalieri 2011, Cavalieri et al. 2012, Cavalieri 2013, Cavalieri, Lenzi and Cantisani 2013, Cavalieri, Camin and Paolucci 2016, Deltenre and Orlandi 2016, Cavalieri, Paolucci and Camin 2018, Cavalieri, Pace and Lenzi 2019. 
Often the data collected in the field are not sufficient to define a complete hypothesis and therefore it is necessary to rely on additional material such as historical and iconographic documents - containing information on the manufacts - testimonies and comparisons (e.g. similar technological solution found on architectures built in the same period).

\section{Research problems and expectations}

The archaeological site of Aiano presents many critical issues due to the state of conservation of the artifacts and the amount of available documentation collected in 15 years of researches. As specified in the previous section, in fact, only the base of the walls is preserved and many decorative elements (such as mosaic tesserae, marbles, stuccoes, fragments of wall paintings) have been systematically found outside their original context as they were dismantled and recycled during the last period of the site's life. It follows that it is no longer possible to determine their precise original location making the interpretation of the decorative apparatus even more complex.

Furthermore, as already said, the central room has a peculiar configuration which turned it into an architectural unicum. Stylistic comparisons and functional analogies are therefore difficult to establish except for technical and architectural aspects.

In the project of the Villa Romana in Aiano, we believe that the use of virtual archaeology as a research tool could offer a valuable contribution to the understanding of the site especially for the late antiquity, preserved only in a residual way.

Our expectation was to exploit the 3D simulation to test and visualize reconstructive hypothesis. It could have helped us to compare the digitized archaeological evidences and interpretations developed the investigations. Furthermore, connecting and organizing in a structured way all the data coming from the archaeological investigations on the $3 \mathrm{D}$ model could have helped to improve the analysis of the monument allowing to refine interpretation, test hypotheses, find new solutions ${ }^{25}$. The present research, limited for now to the area of the so-called "trefoil hall", has involved challenging and complex steps in which we dealt with aspects and problems concerning the integration of gaps, the degree of reliability of the hypothetical reconstruction proposed and the management of "transparency" in the representation of the archaeological data.

\section{Digitisation of the archaeological site}

The first step performed was the geometric acquisition of the archaeological sites in its current state of preservation based on 3D surveying measurements with the

$25 \quad$ Ferdani and Bianchi 2016. 
aim to create a Digital Replica ${ }^{26}$ of the site. The analysis of the architectural complex is a fundamental documentation to operate correctly in the interpretation of the evolutionary phases of the buildings. Nowadays several image-based and rangebased scanning techniques are commonly used in digitization of cultural heritage ${ }^{27}$. In this context we used Dense Image Matching (DIM) techniques. DIM exploit photogrammetry and computer vision algorithms to obtain 3D models of an object along with true color information from a series of photos of an object taken using defined procedures and using specific softwares for image processing and 3D spatial data generation. The survey has been extended to the entire complex, focusing on the units that concern the trefoil hall. The field work was divided into 2 steps: topographic and photogrammetric survey. Since images themselves do not provide metric information, in order to derive metric $3 \mathrm{D}$ results from the photogrammetric procedure, a topographic network of Ground Control Points (GCP) was required. A detailed inspection was carried out in order to plan a survey scheme and locate several checkerboard registration targets as GCP for the construction of a topographic network. Then we started. Firstly, 5 main GCP were placed along the boundaries of the excavation area as topographic bases and then measured with a double differential GPS to be able to geolocate the survey. Subsequently, 20 targets were positioned and measured with a total laser station Topcon GPT7503 positioned and oriented on a GPS basis in order to record data in absolute coordinates. The targets were distributed evenly throughout the surface of the excavation.

Given the dimension of the site we mounted the photographic sensor on a Unmanned Aerial Vehicle (UAV) controlled manually by a pilot using a remote control and a ground station connected with the camera mounted on the UAV, while

Fig. 2. A) registration of topographic GCP with a differential GPS; B) ground control station with 2 remote controllers (for UAV and Gimbal) and 2 monitors connected in streaming with 2 video cameras. The first camera is mounted on the chassis to drive the UAV, and the second one is located on the gimbal to control camera movements.
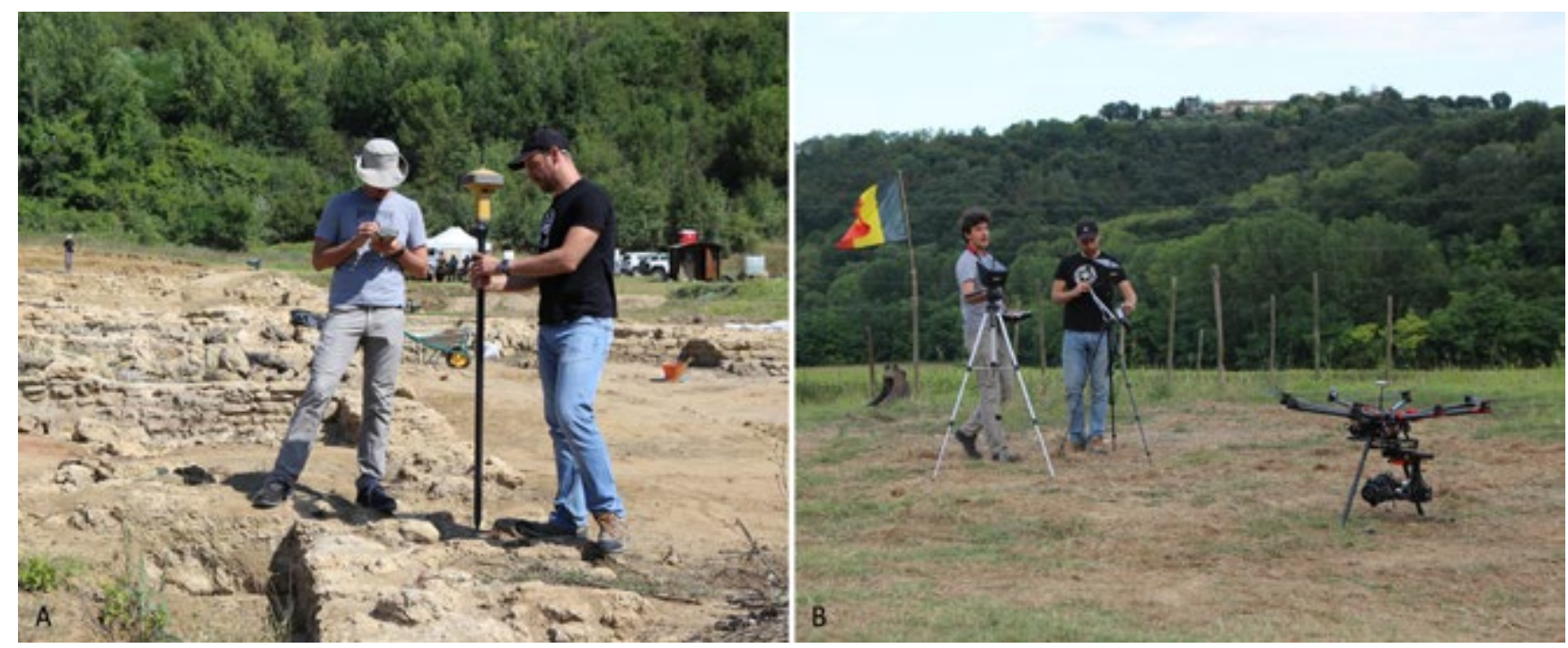

26 Demetrescu et al. 2020.

27 Remondino and Rizzi 2010, Remondino and Campana 2014. 
a camera operator controlled a gimbal system ${ }^{28}$ with a second remote controller in order to orient the camera towards the area to be surveyed (fig. 2).

The camera used is a Canon Eos 6D with a full frame CMOS sensor with a 12.1-megapixel matrix, equipped with a $35 \mathrm{~mm}$ lens, which ensured high quality images to be captured. The camera was programmed to take 1 photo every 2 seconds to cover the entire area and assure sufficient overlaps among photos. The UAV used is an octocopter DJI S1000. It was piloted at approximately $5 \mathrm{~m}$ from the ground level to get the resolution of the photos close to $1 \mathrm{~cm} /$ pix for the trefoil hall and $10 \mathrm{~m}$ for the whole site. 3 Flights and 30 minutes of acquisition were necessary to survey the entire site.

The acquisitions were performed in the evening when the site was completely in the shade of the hills behind it, taking advantage of diffuse light and absence of cast shadows. After some tests we adopted an exposure time of between 1/800 with f/8 of diaphragm aperture and 800 ISO of light sensitivity to obtain aerial images of the site in question. Subsequently, with the same camera, a terrestrial completion measure was carried out for a better coverage of the walls of the roman villa.

The images were processed with Agisoft Photoscan, a photogrammetry software for 3D spatial data generation. After importing images, the associated camera parameters were computed by algorithm of "Structure From Motion" (SFM). Subsequently the software through image matching procedures extracted and matched

\footnotetext{
Fig. 3. Data processing in Photoscan of one of the flights. $\mathrm{Ca}$ mera (blue rectangles) position/orientation reconstruction and features extraction (sparse colored cloud) through SFM algorithms. The result of the photogrammetric process allows to see the path of the cameras, performed during the acquisition, reconstructed in the virtual environment.
}

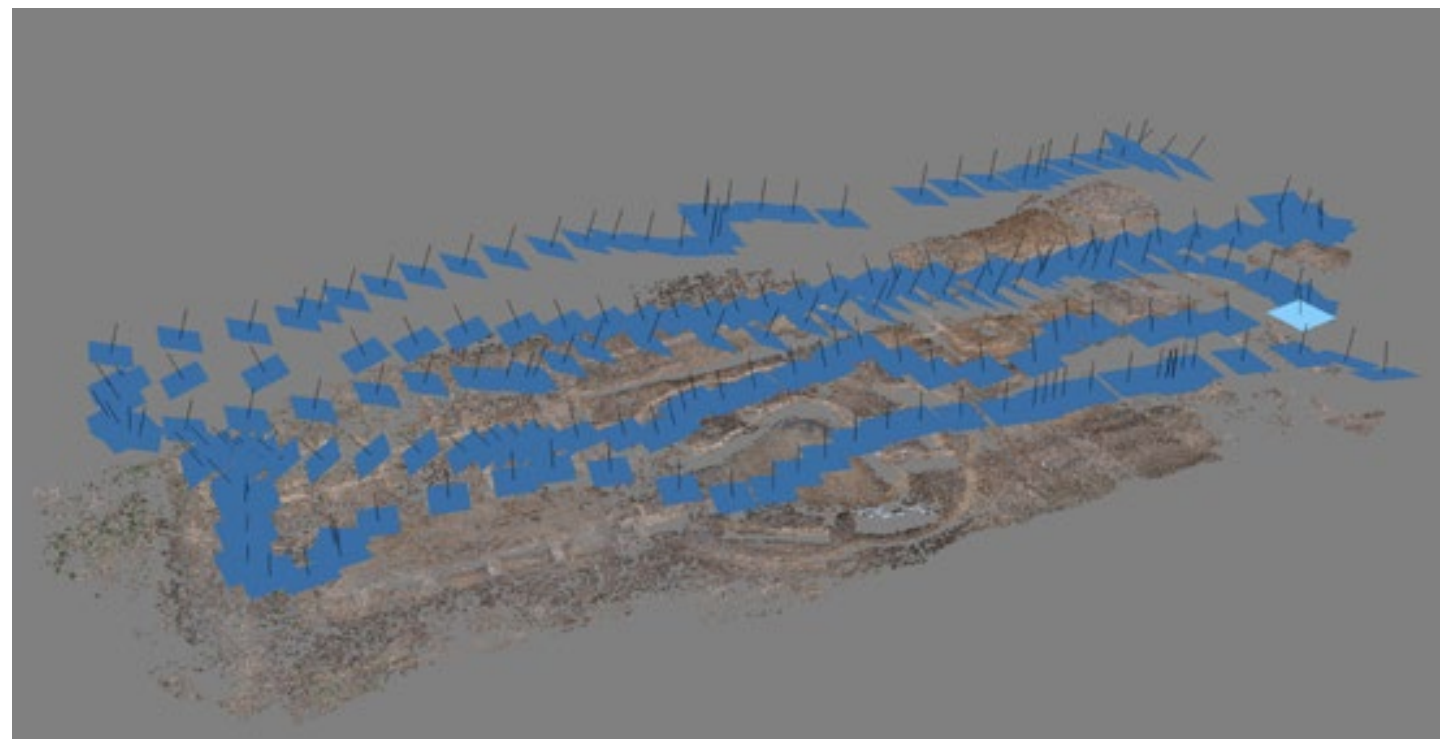

biunivocal correspondence features among images in order to reconstruct camera

28 The gimbal is pivoted support which permits to move the camera along 3 axes and take stable photos from different angles (from 90 to 45 degrees). 


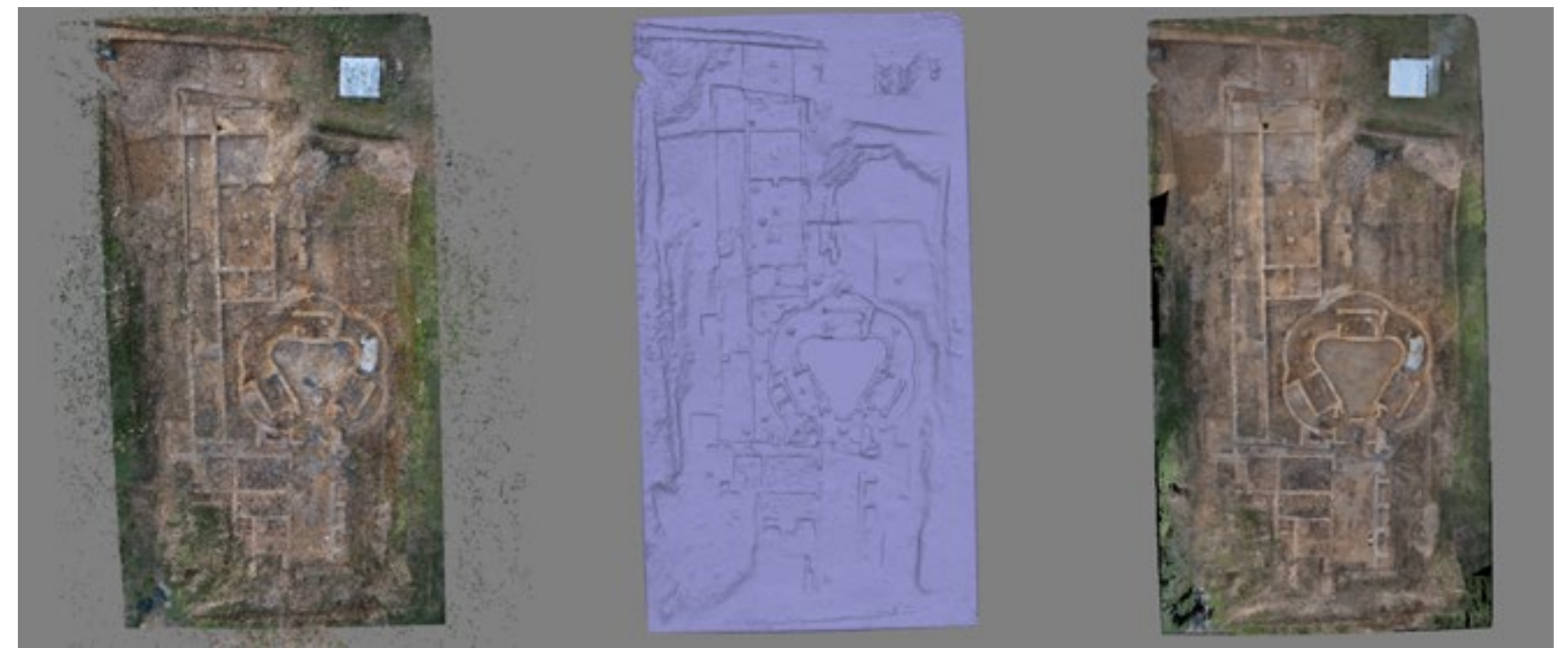

Fig. 4. Data processing in Photoscan. Dense point cloud computation through DSM algorithms; Solid mesh model obtained by point triangulation; Textured model by projection of images.
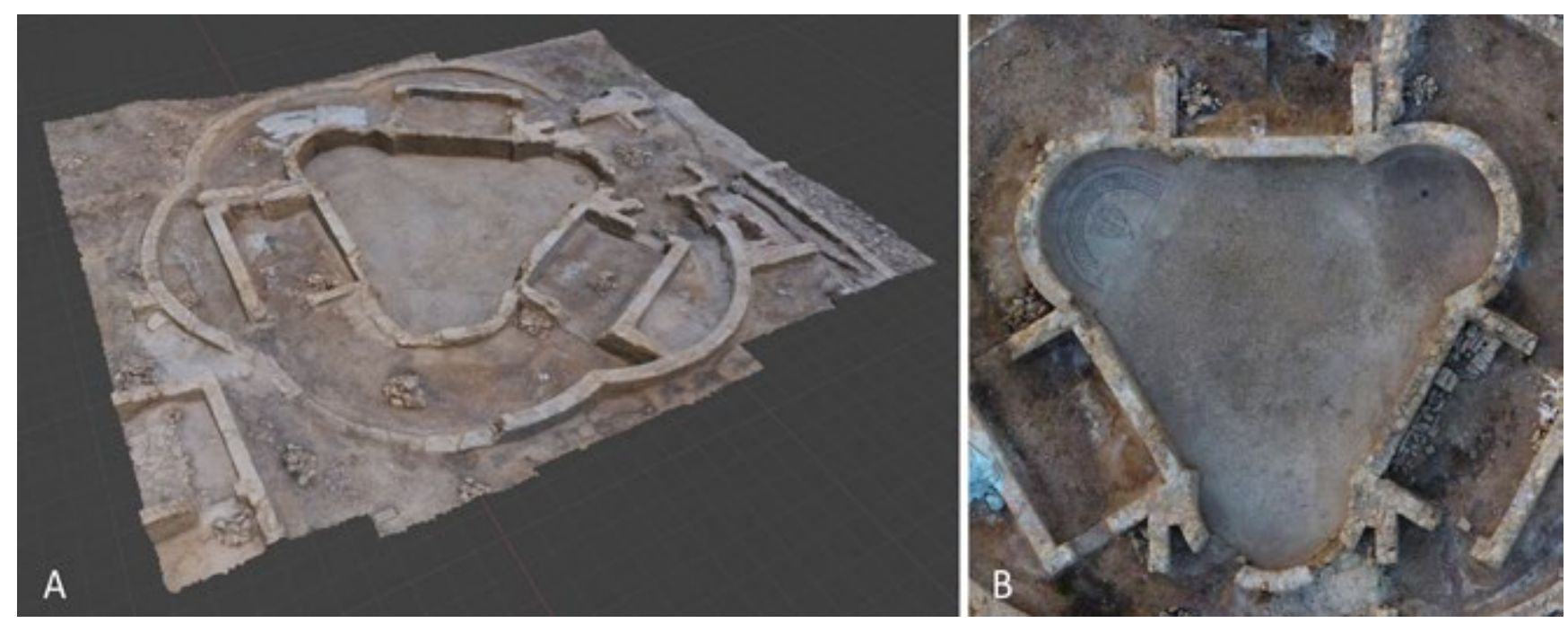

Fig. 5. Outputs of the photogrammetric and optimization processes. A) digital model of the trefoil hall, in its current state of preservation, visualized in a computer graphic software (Blender); B) high-resolution orthoimage of the hall.

position and orientation in space. After these steps the features extracted were associated to $3 \mathrm{D}$ points resulting in a sparse point cloud (fig. 3).

Then the dense point cloud was computed by algorithms of "Dense Stereo Matching” (DSM) employing all the pixels of the images. Finally, the points are triangulated to obtain a mesh models with texture containing color information derived from images (fig. 4).

The topology of mesh was optimized using remeshing filters in CloudCompare software. This way it was possible to simplify the model by reducing the number of polygons but, at the same time, to preserve texture and geometric quality 
Fig. 6. A) a collapsed brick arch found in the north-east apse of the trefoil hall; $B$ ) traces of the collapsed plasters that covered the ceiling; $C$ ) roman tiles found during the excavation. in those parts with complex geometry and architectural details (such as mosaics). The topographic network of points previously gathered with the total station was appended to the model in order to scale and geo-reference the digital replica of the site and control faults and distortions. Finally, the 3D model obtained was also used to obtain high-resolution orthoimages of the site (plans and sections) from different orthometric point of views (fig. 5).

\section{Source collection and management}

Historical and archaeological sources useful for supporting the philological interpretation and designing reconstructive hypotheses were collected. According to the 3rd principle of the London Charter "In order to ensure the intellectual integrity of computer-based visualization methods and outcomes, relevant research sources should be identified and evaluated in a structured and documented way" ${ }^{29}$. Indeed, the reliability of the interpretation, is influenced by the meticulousness of the work of collecting and managing these data ${ }^{30}$. For this purpose, a team of experts, which over the years has followed the activities of excavation and research of the villa, has been teamed up in order to structure and select all the available documentation relating to the trefoil hall. The data used were as follows:

- metric survey of the extant structures over the years (2D-3D snapshots made in a given moment in time).

- photos and sheets of collapsed structures (Special Finds - SF) whose original position is inferable. E.g.: collapsed brick arches belonging to the vaults of the apse rooms (fig. 6, A); collapsed false ceilings - made by wooden arches, reeds, and plaster - (fig. 6, B).

- photos and sheets of fragments (SF) found not in situ as roof tiles and travertine stones for the walls (fig. 6, C).
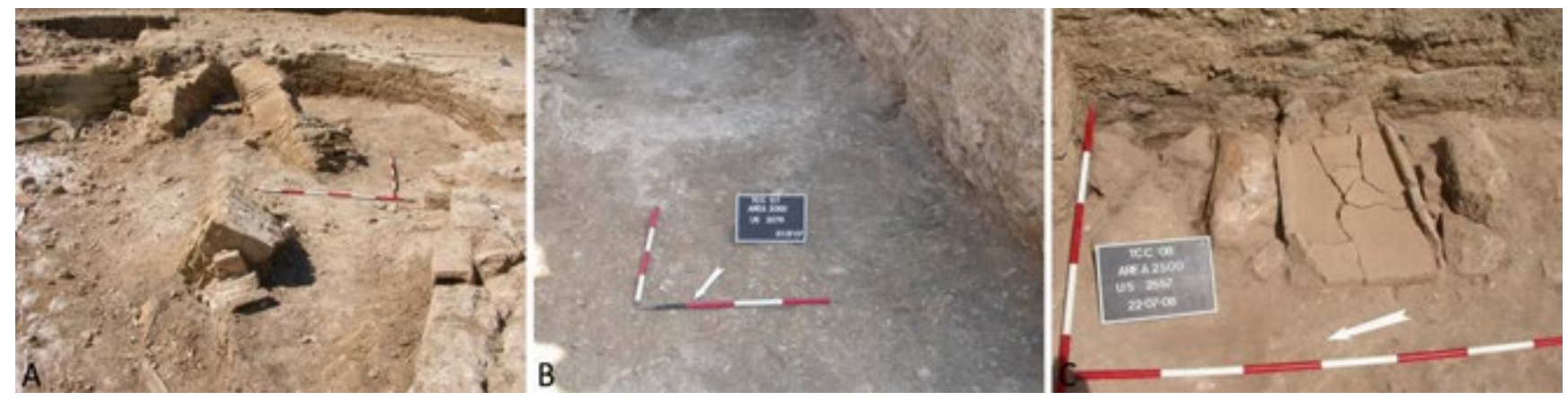

29 http://www.londoncharter.org/principles/research-sources.html

30 Gabellone 2018 
- photos and sheets of archaeological finds (SF) found not in situ and moved from their original context (spolia) such as marble, glass sectilia, mosaics, frescoes and stuccoes (these archaeological materials were found in the site, but their original position and complete decorative schema is unknown)

- archaeological reports and drawings (sources).

- theoretical building rules, theory of proportion and roman modules ("assumption" sources) $)^{31}$. Existing structures show measures attributable to multiples of the Roman foot (fig. 6 A and C)

- comparison with other still-preserved buildings with similar structural or functional solutions (sources).

The use of comparisons always requires a lot of caution because there is the risk of creating prototypes or models that could have never existed. In this case, the architectural uniqueness, has not allowed to identify relevant comparisons belonging the same period and therefore it was necessary to expand the chronological range. Given that, structural comparisons were made with late antique buildings from the fifth century of the Ravenna territory, such as the Mausoleum of Galla Placidia, the baptistery of the Arians and the Basilica of San Vitale. Functional comparisons have been made with some poly-lobed rooms of the villa of Cazzanello in Tarquinia and Casale in Piazza Armerina.

Fig. 7. Reconstructive volumes of the hall realized through polygonal modelling directly on the digital replica of its actual state of conservation and chart of the reconstruction process.

\section{Interpretation and 3D mo-} delling

All the data collected were cross-referenced and analysed together with the scientific committee in order to conjecture a reconstructive hypothesis that was then simulated through 3D modelling techniques. 3D modelling was integrated in the interpretation processes and supported them through simulations. A first draft simulation of the hall was designed with computer graphic software

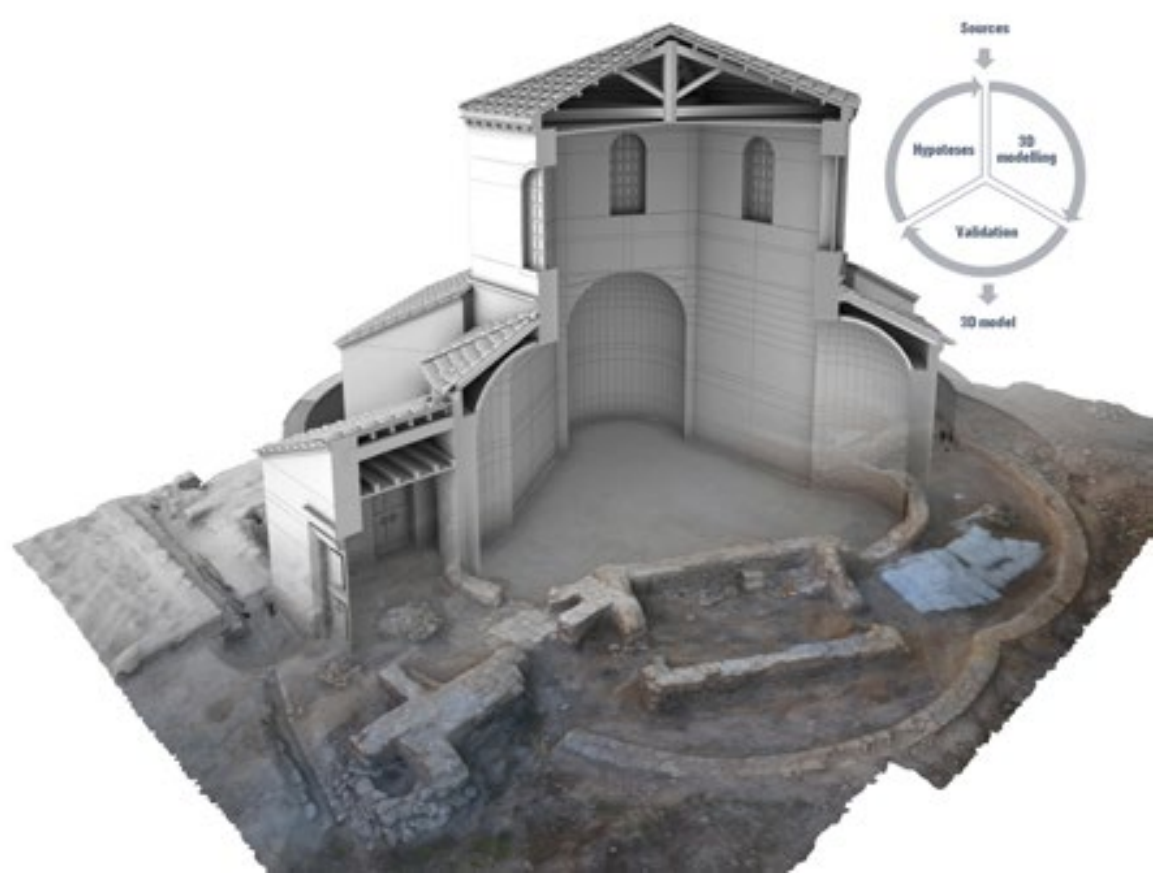

31 Pollio 2013 
giving the archaeological remains architectural completeness. The reconstruction was modelled on top of the digital replica and inherits its correct measures and proportions allowing great accuracy and control during the process thus avoiding the most common problems encountered when using two-dimensional drawings. Overlapping digital replica of the site and its reconstruction made possible realtime comparisons of dimension, orientation, height and stratigraphic units making the connection between archaeological data and 3D model understandable and helping the archaeologists to validate the proposed hypotheses.

Each version of the virtual model of the hall was evaluated until the scientific committee approved a final version, philologically more reliable, discarding those that are fallacious or less probable. Give that, the reconstruction can be considered cyclical process since is repeated every time the model is modified (fig. 7).

Being the sources insufficient to reconstruct the entire building, simulations were crucial to test and visualize speculations. The most challenging parts to be digitally rebuilt were the roofing system and the elevated wall of the trefoil hall.

Given that, not only the visible structure but also the hidden architectural elements, such as attics, wooden frames of the false vaults and ceilings, were modelled in order to carry out a plausible simulation of the elevations. Firstly, the tiles and embrices were modelled based on the measurements of the intact structures. Subsequently, they were distributed over the entire surface of the roof in order to assume, with a good approximation, the number of elements and their total weight. Therefore, it was possible to suppose the type of wooden infrastructure for supporting the roofs. The hypothesis of the existence of vaults in masonry was rejected both because no archaeological remains were found and because of the excessive load on the wall structures. In order to estimate the effects of loads on structures, we didn't use any structural analysis based on mathematical simulation as Finite Element Method (FEM). Certainly, such analyses could have contributed to evaluate our hypothesis, however it must be noted that FEM results are not always decisive but they strongly depend on the exactness of mechanical parameters, which often are difficult to evaluate especially in the cases of historical building ${ }^{32}$. In this case we based on data collected (absence of evidences), comparisons and empirical data (wall thickness). In addition, the discovery of fragments of plaster made by wooden reeds and mortar have led to the hypothesis of the presence of suspended ceilings (USV 206 -220) and false vaults (USV211).

Regarding the central area of the hall, a structural comparison was made with the Ravenna structures previously mentioned. Basing on these comparisons, it was assumed that the central area had to be higher than the surrounding three apses and rectangular rooms. In fact, considering the shape of the building, it was assumed

32 Frunzio et al. 2001, p. 598. 

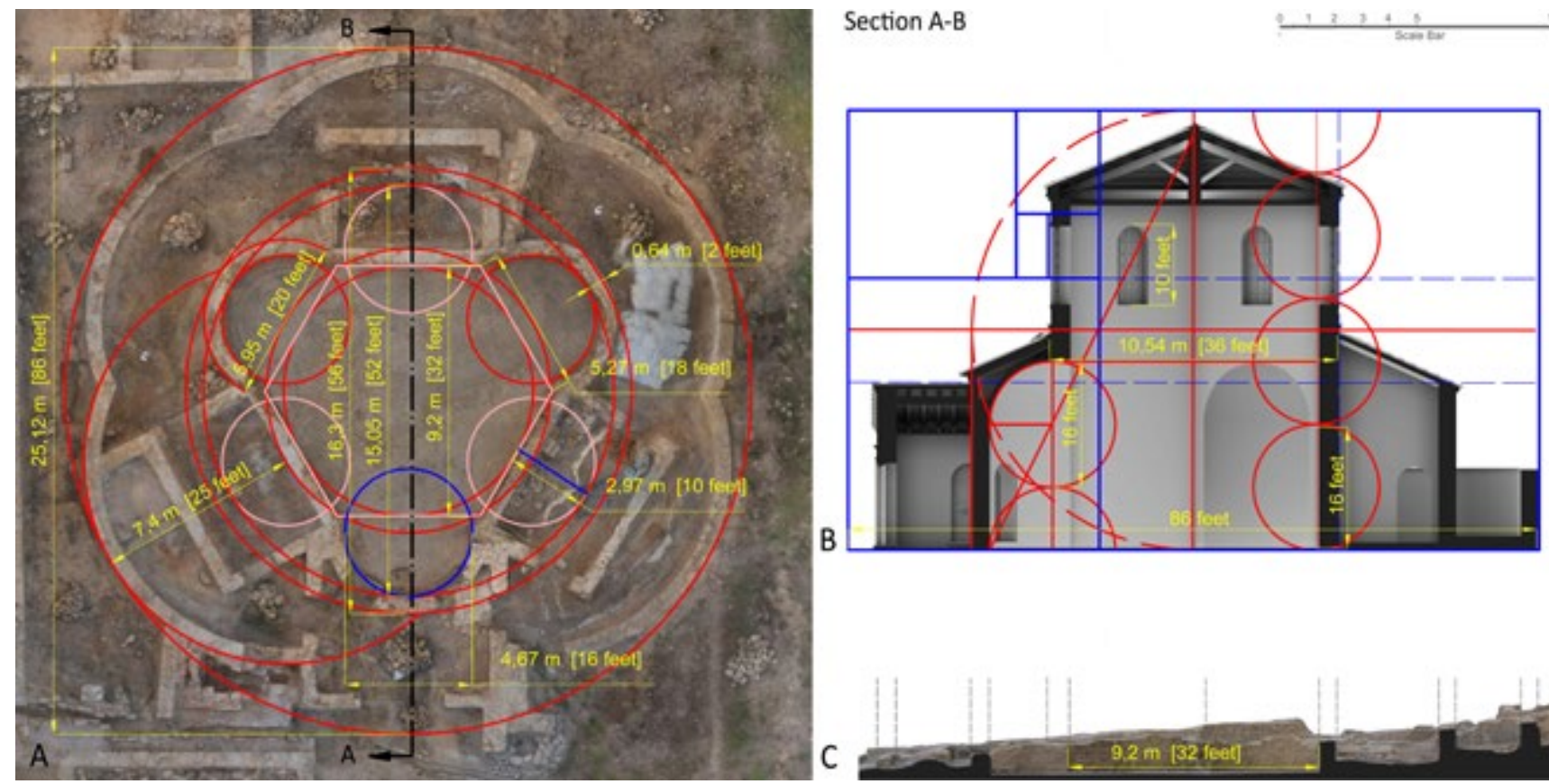

that the central room would necessarily be illuminated by a light source coming from above. Furthermore, the apses were originally surmounted by brick arches which enclosed the central space within a hexagon (fig. 8, A). Given that, the hexagonal prism was considered the most logical and functional geometric solid form to complete the upper part of the hall.

Other than comparison and structural issues, the height of the walls was assumed considering also the multiples of the Roman foot ${ }^{33}$ and according to the architectural proportional systems found in the plan of the building (fig. 8, A).

The design scheme identified in the plan, is characterized by a strong formal rigor, symmetry and harmony in proportions. These aspects depend on mathematical relationship between the architectural parts. The measurements found are multiple of the Roman foot. The original design of the plan with six apses is obtained from an intersection of major (lobes of the ambulatio) and minor circles (diameter of the apses) which have geometric ratios of 1:1 and 1:2.

Given that it seemed that the plan of the building was based on a module (a part providing the reference unit for the whole architecture ${ }^{34}$ : the diameter of an apsis (external 20 feet; internal 16 feet). We adopted this module to estimate walls elevation (fig. 8, B). Obviously other proportional solutions were possible but this one was chosen for two reasons. The first is the symmetry. The building has a width-

33 According to latin authors the "Roman foot" is $29,6 \mathrm{~cm}$ (Giuliani 1990, p. 283). However, since the end of the 3 rd century is attested the "Byzantine foot" which measures 31,48 cm (Salvatori 2006,6 ). In our case the average measure is around $29,6 \mathrm{~cm}$.

34 Gangwar 2017. 
Fig. 9. Extended Matrix of the trefoil hall and an applied example of virtual stratigraphy with related metadata and paradata. to-height ratio of 1:1 - 1,6:1 considering the ambulatio - and the ratio between the height of the central room and the apses of 1:2. The ratio between the diameter of the apses and the diameter of the lobes of the ambulatio is also 1:2. Similar ratios and symmetric proportions can also be observed in other late antique buildings (although belonging to other contexts and with different functions). The second is that higher walls could have overloaded the structure considering their thickness. However, this interpretation might be updated with new hypotheses following future discoveries.

As pointed out in the previous paragraph, archaeologists very often criticize the value of virtual reconstructions aimed at public dissemination because they risk conveying the wrong message, namely that the reconstruction is the truth instead of a possible interpretation of the past. Moreover, such reconstructions are "black box" and the source and interpretative reasoning is not declared. In order to overcome such issue during the reconstruction we registered all the procedure using the Extended Matrix approach ${ }^{35}$.

Extended Matrix (EM) is a visual node-based formal language based on a stratigraphic approach in use in archaeology. The term "extended" indicates that it includes and defines not only archaeological stratifications (the superimposition of single units of stratigraphy) but also their hypothetical reconstructions (the Virtual Stratigraphic Unit - USV). Given that using EM it was possible to account, in graph database, the sources used and the interpretation processes (paradata) that

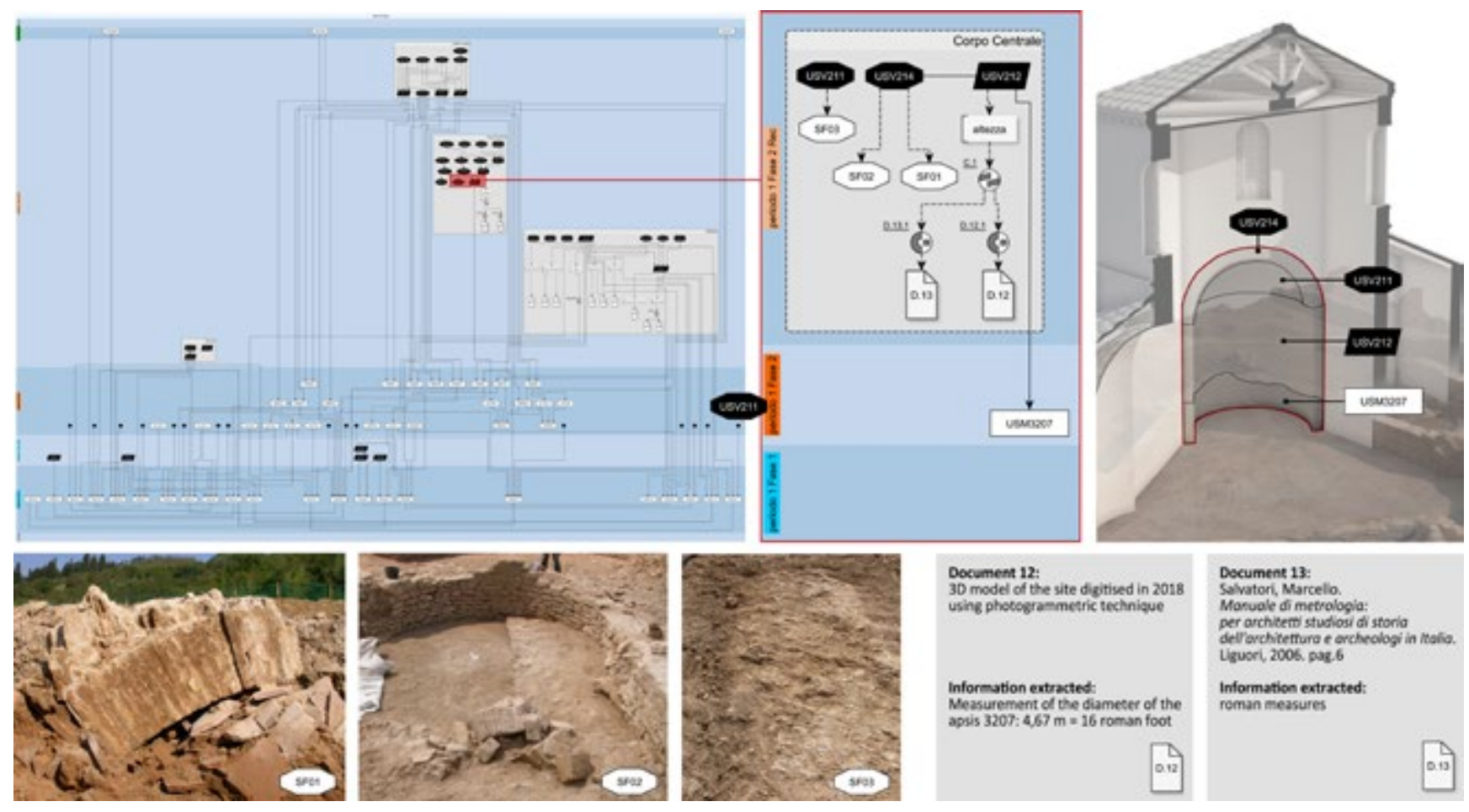

35 Demetrescu 2015, Demetrescu 2018, Demetrescu et al. 2016 
have led from archaeological evidences to the reconstructive hypothesis. Finally, through computer graphic tools in the software Blender it was possible to connect sources and paradata with the virtual reconstruction creating semantic transparent models (fig. 9).

In the semantic model of the polylobed hall all the architectural or stratigraphic elements were associated with a node entity that describes their properties (description, physical properties, temporal relations, etc.) in the graph database. This 3D model is called "proxy", namely a simplified prototype which allows to visualize and interrogate the extended matrices containing excavation information and the sources used in the reconstructive process (comparisons, assumptions, Roman architectural rules) in order to help researchers in refining the final reconstructive hypothesis.

Furthermore, the Proxy model allows a conceptual visualization using different colour coding. In our case two colour codification was created. The former highlights, in the digital replica, the different building phases (fig. 10, A). The latter shows, in the reconstructive model, the different level of certainty basing on archaeological evidences. The colours distinguish extant structures (red) and repositioned fragments (yellow) from their completion and hypothetical reconstruction (blue). The green colour finally paints all those parts for which we have no structural or archaeological evidences, but their reconstruction is entrusted to comparisons or interpreted sources (fig. 10, B).
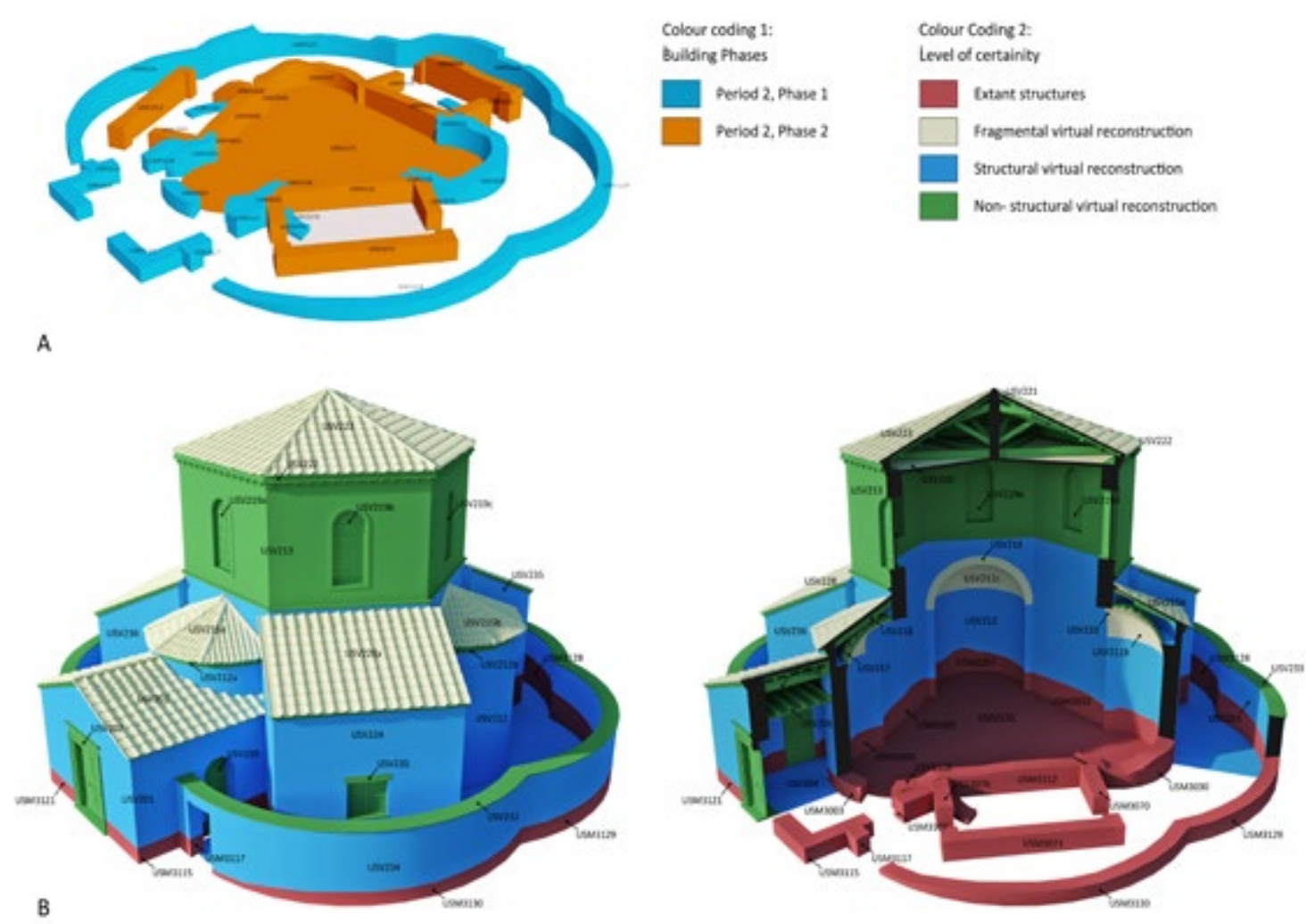
Fig. 11. Trefoil Hall: graphic representation of the hypothetical reconstructive model (period 2,

phase 2 - end of 4 th

- beginning of the 5 th century).
After completing the interpretative process and approving the final reconstructive hypothesis, the final representation model for a realistic visualization was created. Through the use of polygonal modelling, details were added and the materials that make up the structure (plaster, wood, terracotta, travertine) were characterized. Into practice the physical behavior of materials was simulated in computer graphic through the use of textures - which represent the base chromatic information and were created from photographs - associated with shaders that control characteristics such as reflection, refraction, roughness etc. It is a "figurative" model, and although the complexity is optimized to respond to operational needs, it satisfies characteristics such as the recognition of the geometry and the characterization of surfaces with realistic chromatic information (fig.11).
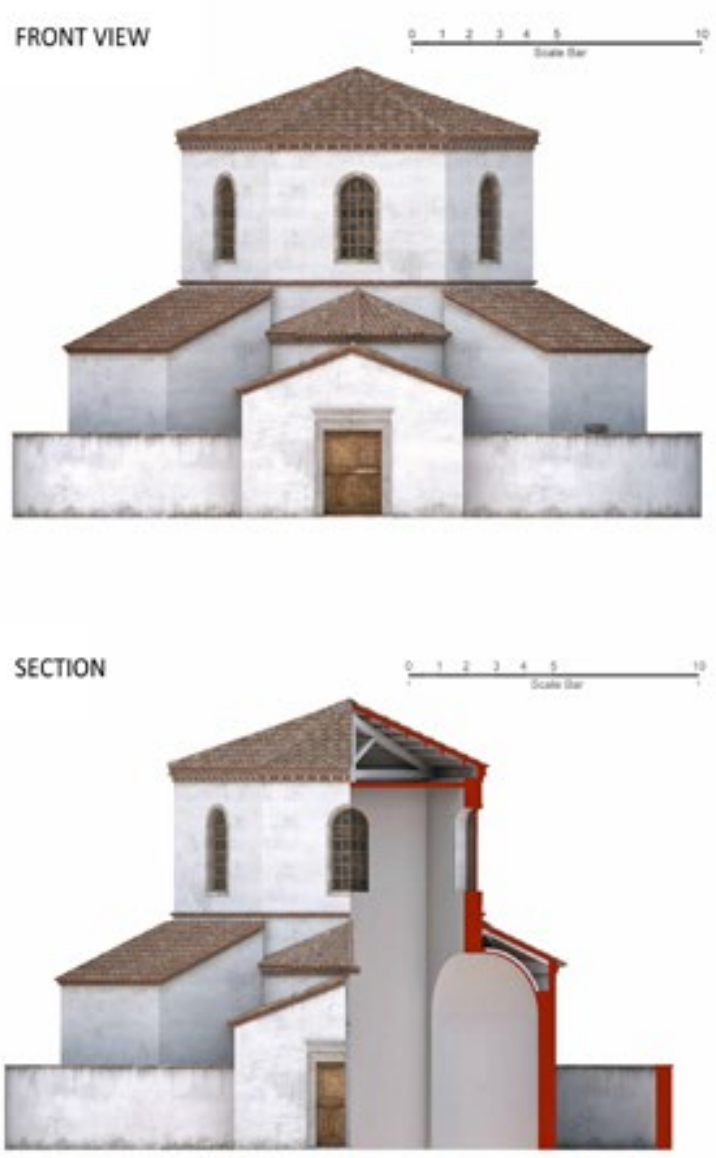
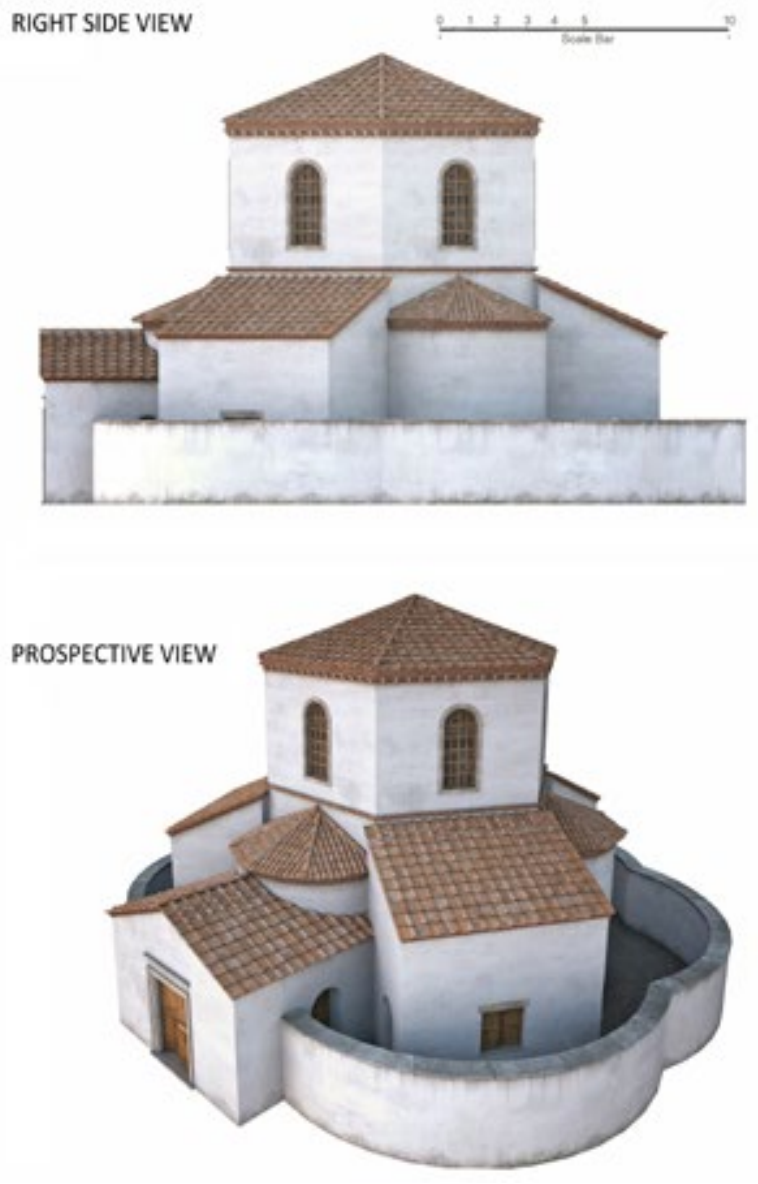


\section{Conclusion}

The article shows how the use of 3D modelling and visualization applied to archaeological contexts can improve the interpretation of artefacts through simulations and cognitive aspects.

In the presented case study is clear that, even before its publication, 3D models have played an important role in supporting research, allowing discussion and comparison of interpretative hypotheses and their verification through simulations and visualization. From a communicative point of view, the use of the EM tool for a "transparent" presentation and management of archaeological data and paradata, improved cognitive processes by transforming the raw data into visual information.

\section{Reference List}

Ask, Carolina. 2012. Interpreting in 3D - Employing 3D Modeling in Field Archaeology from Research and Public Communication Perspectives. Master's Thesis in Archaeology, Lund University.

Baker, Drew. 2012. "Defining Paradata in Heritage Visualization." In Paradata and Transparency in Virtual Heritage, 238-251. Routledge.

Barceló, Juan A, Maurizio Forte, and Donald H Sanders. 2000. Virtual Reality in Archaeology. Archaeopress Oxford.

Beacham, Richard, Hugh Denard and Francesco Niccolucci. 2012. London Charter for the Computer-Based Visualization of Cultural Heritage.

Cavalieri, Marco. 2009. "Vivere in Val d'Elsa tra tarda antichità e alto medioevo. La villa romana di Aiano-Torraccia di Chiusi (Siena, Italia).” FOLD\&R FastiOnLine Documents \& Research, no. 156, 1-18.

Cavalieri, Marco. 2010. "Il pavimento in cementizio della villa tardoantica di AianoTorraccia di Chiusi (Siena). Primi dati su decorazione musiva, tecnica esecutiva e orizzonte cronologico.", in C. Angelelli, C. Salvetti, Atti del XV Colloquio dell'Associazione Italiana per lo Studio e la Conservazione del Mosaico (AISCOM), Aquileia, 4-7 Febbraio 2009: 365-376. Tivoli: Scripta Manent.

. 2011. "Dalle tessere alle collane. La rifunzionalizzazione della villa tardoantica di Aiano - Torraccia di Chiusi (San Gimignano, SI) e il reimpiego dei suoi mosaici parietali in pasta vitrea.", in Atti del XVI Colloquio dell'Associazione Italiana per lo Studio e la Conservazione del Mosaico (AISCOM), Palermo, 17-19 Marzo 2010, Piazza Armerina, 20 Marzo 2010, edited by C. Angelelli: 613-626. Tivoli: Scripta Manent.

2013. "Quid igitur est ista villa? L'Etruria centro-settentrionale tarda antichità e alto medioevo. Nuovi dati e vecchi modelli a confronto sulla villa d'Aiano-Torraccia di Chiusi (Siena, Italia)." In Leben Auf Dem Lande: Der Fundplatz ,Il Monte 'bei San Gimignano: Eine Römische Siedlung Und Ihr Kontext (Jena, 19-21 Juni 2009): 283-319, Wien: Phoibos Verlag. 
Cavalieri, Marco, E Boldrini, Ch Bossu, P De Idonè, and A Fumo. 2012. "Aspetti della cultura materiale nelle fasi di riutilizzo (V-inizi VII Sec. d.C) della villa romana di Aiano-Torraccia di Chiusi (San Gimignano, Siena/Italy). Note preliminari." Rei Cretariae Romanae Fautorum Acta 42: 169-180.

Cavalieri, Marco, Lorenza Camin, and Fabrizio Paolucci. 2016. "I sectilia vitrei dagli scavi della villa romana di Aiano-Torraccia di Chiusi (Siena, Toscana)." Journal of Glass Studies 58: 286-291.

Cavalieri, Marco, S Lenzi, and E Cantisani. 2013. "La fine della villa tardoantica di Aiano - Torraccia di Chiusi (San Gimignano, Siena). La sistematica distruzione dei suoi arredi. Nuovi dati archeologici su litotipi e sistemi decorativi", in Atti del XVIII Colloquio dell'Associazione Italiana per lo Studio e la Conservazione del Mosaico (AISCOM), Cremona, 14-17 Marzo 2012, edited by C. Angelelli: 537-544. Tivoli: Scripta Manent.

Cavalieri, Marco, and Gloriana Pace. 2011. "Metodologie geofisiche a confronto presso la villa tardoantica di Aiano-Torraccia di Chiusi (Siena): Qualche nota su efficacia e limiti." Archeologia E Calcolatori 22: 283-306.

Cavalieri, Marco, Gloriana Pace, and Lenzi Sara. 2019. "Aiano-Torraccia di Chiusi (San Gimignano, Siena): A Roman Villa in Central Italy during Late Antiquity.", in The fifth century: Age of Transformation. Proceedings of the 12th Biennial Shifting Frontiers in Late Antiquity Conference, edited by J.W. Drijvers and N. Lensky: 93103. Bari: Edipuglia.

Cavalieri, Marco, Fabrizio Paolucci, and Camin Lorenza. 2018. "Alexandrina Luxuria Nella Toscana Tardoantica. Forme E Apparati Decorativi Presso La Villa Di Aiano-Torraccia Di Chiusi.", in Abitare nel Mediterraneo Tardoantico. Atti del II Convegno del Centro Interuniversitario di studi sull'Edilizia tardoantica nel Mediterraneo (CISEM), Bologna 2-5 Marzo 2016, edited by di I. Baldini, C. Sfameni: 493-498. Bari: Edipuglia.

Clark, Jeffrey T. 2010. "The Fallacy of Reconstruction.”, in Introduction to CyberArchaeology edited by M. Forte. Oxford: Archaeopress, 63-74.

Deltenre F.D, and L. Orlandi. 2016. "«Rien ne se perd, rien ne se crée, tout se transforme» Transformation and Manufacturing in the Late Roman Villa of Aiano-Torraccia di Chiusi ( $5^{\text {th }} 7^{\text {th }}$ cent. AD"), Post-Classical Archaeologies, 6, 71-90.

Demetrescu, Emanuel. 2015. "Archaeological Stratigraphy as a Formal Language for Virtual Reconstruction. Theory and Practice.” Journal of Archaeological Science 57: 42-55.

2018. "Virtual Reconstruction as a Scientific Tool: The Extended Matrix and Source-Based Modelling Approach." In Digital Research and Education in Architectural Heritage, 102-116. Springer, 2018.

Demetrescu, Emanuel, Daniele Ferdani, Nicolò Dell'Unto, Anne-Marie Leander Touati, and Stefan Lindgren. 2016. "Reconstructing the Original Splendour of the House of Caecilius Iucundus. A Complete Methodology for Virtual Archaeology Aimed at Digital Exhibition." SCIRES-IT-SCIentific RESearch and Information Technology 6 (1): 51-66.

Demetrescu, Emanuel, Enzo d'Annibale, Daniele Ferdani, and Bruno Fanini. 2020. "Digital Replica of Cultural Landscapes: An Experimental Reality-Based Workflow 
to Create Realistic, Interactive Open World Experiences." Journal of Cultural Heritage, $41,125-141$.

Denard, Hugh. 2012. A New Introduction to the London Charter. Paradata and Transparency in Virtual Heritage. Digital Research in the Arts and Humanities Series. Ashgate.

Denard, Hugh. 2013. "Implementing Best Practice in Cultural Heritage Visualisation: The London Charter." In Good Practice in Archaeological Diagnostics edited by C. Corsi, B. Slapšak, and F. Vermeulen, 255-268. Cham: Springer.

Ferdani, Daniele, and Giovanna Bianchi. 2016. "Recording, preserving and interpreting a Medieval Archaeological Site by Integrating Different 3D tehcnologies." In CAA 2015. Proceedings of the 43rd Annual Conference on Computer Applications and Quantitive Methods in Archaeology, edite by S. Campana, R. Scopigno, G. Carpentiero, M. Cirillo. Oxford: Archaeopress, 213-225.

Ferdani, Daniele, Sofia Pescarin, Bruno Fanini, Ivana Cerato, and Guido Lucci Baldassari. 2014. "Handling Transparency in 3d Reconstructed online Environments: Aquae Patavinae vr Case Study." In Archaeology in the Digital Era : Papers from the 40th Annual Conference of Computer Applications and Quantitative Methods in Archaeology (CAA), Southampton, 26-29 March 2012, edited by G. Earl, and P. Verhagen: 165-173. Amsterdam: Amsterdam University Press

Forte, Maurizio. 2000. “About Virtual Archaeology: Disorders, Cognitive Interactions and Virtuality.", in Virtual reality in archaeology : computer applications and quantitative methods in archaeology (CAA), edited by M. Forte, J. A Barceló, and D. Hugo Sanders. BAR International Series 843: 247-259. Oxford : BAR Publishing.

Forte, Maurizio. 2010. "Introduction to Cyber-Archaeology." Cyber Archaeology. BAR. International series, 2177, 9-13. Oxford : Archaeopress.

Frischer, Bernard, Franco Niccolucci, Nick S Ryan, and Juan A Barceló. 2002. "From CVR to CVRO: The Past, Present, and Future of Cultural Virtual Reality.", in Virtual archaeology : proceedings of the VAST Euroconference, Arezzo 24-25 November 2000, edited by F. Niccolucci. BAR International Series 1075: 7-18. Oxford: Archeopress.

Frunzio, G., Monaco, M. and Gesualdo, A., 2001. "3D FEM analysis of a Roman arch bridge". Historical constructions, 591-598.

Gabellone, Francesco. 2018. "The reconstruction of archaeological contexts: a dialectical relationship between historical-aesthetic values and principles of architecture." In Sensing the Past: from artifact to historical site., edited by N. Masini, and F Soldovieri: 395-417. Cham: Springer.

Gangwar, Gaurav. 2017. "Principles and Applications of Geometric Proportions in Architectural Design." International Journal of Civil Engineering and Technology 4.3: 171-176.

Giuliani, Cairoli Fulvio. 1990. L'edilizia nell'antichità. Roma: Nuova Italia scientifica

Hermon, Sorin, and Franco Niccolucci. 2018. "Digital Authenticity and the London Charter.", in Authenticity and cultural heritage in the age of $3 D$ digital reproductions, edited by P. Di Giuseppantonio Di Franco, F. Galeazzi, and V. Vassallo: $37-$ 47. Cambridge: McDonald Institute. 
Hermon, Sorin, and Joanna Nikodem. 2007. "3D Modelling as a Scientific Research Tool in Archaeology." In 11th CAA International Computer Assisted Assessment Conference : proceedings of the conference on 10th \& 11th July 2007 at Loughborough University, edited by F. Khandia: 1-6. Loughborough : Professional Development

Pollio, Marcus Vitruvius. 2013. De architectura: libri decem. London: Elsevier.

Reilly, Paul. 1990. "Towards a Virtual Archaeology." In Computer applications and quantitative methods in archaeology : 1990, edited by K. Lockyear, S. P. Q. Rahtz, and C. Orton: 133-139. Oxford: British Archaeological Reports.

Remondino, Fabio, and Alessandro Rizzi. 2010. "Reality-Based 3D Documentation of Natural and Cultural Heritage Sites - techniques, Problems, and Examples." Applied Geomatics 2 (3): 85-100.

Remondino, Fabio, and Stefano Campana, eds. 2014. 3D recording and modelling in archaeology and cultural heritage. BAR International Series 2598.

Salvatori, Marcello. 2006. Manuale di metrologia: per architetti studiosi di storia dell'architettura e archeologi in Italia. Liguori.

Sanders, Donald H. 2008. "Why Do Virtual Heritage." Online Features Article, Archaeology Archive. Published on 13.03.2008. 
